\begin{tabular}{|cc|c|}
\hline ISSN (Online): 2367-6957 & ISSN (Print): 2367-6361 \\
Izvestiya Journal of Varna University of Economics 3 (2020) \\
J Z V E S T I Y A
\end{tabular}

\title{
MANAGING EXCHANGE RATE RISK WITH DERIVATIVES: AN APPLICATION OF THE HEDGE RATIO
}

\section{Consuela-Elena POPESCU ${ }^{1}$, Georgiana VRÎNCEANU' ${ }^{2}$, Alexandra HOROBET ${ }^{3}$, Lucian BELAȘCU ${ }^{4}$}

${ }^{1}$ The Bucharest University of Economic
consuela.popescu@rei.ase.ro

JEL: G32, F23

\begin{abstract}
Risk management practices have become increasingly sophisticated. Derivatives have been developed and they can be widely used by economic agents in order to effectively hedge the risk, or by those who want to speculate on the evolution of prices. This study presents a hedging alternative with future contracts using an ARMA/ARIMA model. Employing five futures contracts on several exchange rates AUD/CAD, EUR/JPY, EUR/USD, GBP/USD, RMB/USD - the actual value of the base at a future time (defined as the difference between spot rate and futures rate) can be predicted with a certain number of days until maturity. Apart from the classical calculation of the hedge rate this is another method for hedgers to use in order to reduce the volatility of their positions by trying to predict the future spot price in the currency market.
\end{abstract}

Key words:

exchange rate risk, hedging, ARMA, futures, stock exchange.
(C) 2020 University of Economics - Varna

Citation: POPESCU, C.-E., VRÎNCEANU, G., HOROBET, A., BELAȘCU, L. (2020). Managing Exchange Rate Risk with Derivatives: An Application of the Hedge Ratio. Izvestiya Journal of Varna University of Economics, 64 (3), p. 316 - 327. DOI: 10.36997/IJUEV2020.64.3.316 


\section{Introduction}

This paper presents various aspects related to hedging with futures contracts and, in particular, a special approach to hedging with derivative instruments, by using simple econometric models such as ARMA (Autoregressive Moving Average Process). The modelling part of the paper includes a case study, which exposes a different way to achieve hedging by trying to predict the base (the difference between the spot price and the futures price). Using data on five futures contracts and modelling the bases of these contracts in a time series framework, a methodology for forecasting the base is presented using the ARMA econometric model. The paper concludes with the main findings and recommendations of the case study.

Whenever a company's transactions cross national borders, exchange rate fluctuations influence those transactions. Exchange rate fluctuations can lead to large variations in relative costs between firms located in different countries and affect the prices of goods sold in domestic and foreign markets (Adler, 1984). Due to the uncertainty that often hovers over the financial markets, but not only, the volatility of commodity and stock prices, interest rates, and exchange rates, the need for economic agents to cover these risks arose (Andersen et al, 2003; Schena, 2007). Risk management has become an increasingly sophisticated process (Hagelin, 2003; Hennings, 2004; Su, 2018). Thus, derivative instruments (futures, options, swaps, etc.) and combinations of them have been developed, and they can be used by economic agents in order to effectively hedge the risk, but also by those who want to speculate on the evolution of prices, exchange rates or by those who want to take advantage of arbitrage opportunities. However, in this paper we delve into the use of derivative instruments to cover financial risks, a process called hedging in literature.

Hedging is a type of transaction that limits investment risk, using derivative financial instruments, such as options and futures. Typically, hedging transactions involve taking opposite positions in the market in order to ensure a certain gain or loss on a transaction (Alvaro et al, 2016). They are employed by portfolio managers to reduce portfolio risk and volatility, but also to increase profits through selective hedging (Solomon et al, 2000; Brown et al, 2006; Francis et al, 2007).

The central theory of hedging considers that the price of the underlying asset fluctuates in a manner similar to the price of the asset that is the subject of the futures contract (Hull, 2018; Johnson, 1976; Collins, 1997; Smith and Stulz, 1985). If an investor is long (short) on the underlying (usually, spot) asset and wants to protect himself against a decrease (increase) in the price, he can take a short (long) position on the futures. The sale (purchase) of futures contracts thus replaces the sale 
(purchase) of the underlying asset. As the hedger is short on the futures contract, he can, depending on how effective the hedging is, buy again (resell) the futures contract at a lower (higher) price, thus generating a gain that compensates for the loss recorded on the spot market. If spot and futures prices are strongly correlated, hedging reduces a substantial part of the risk.

The hedging strategy depends on the risk faced by the hedger (Schweizer, 1994; Howe et al, 1996). This must be determined so that the position on the futures is profitable and offsets the loss recorded by the spot position. Hedging is effective when the potential losses on the spot market are minimized. In such situations, the profit (loss) on the futures market offsets the loss (profit) on the spot market, eliminating the hedger's risk. Perfect hedging is possible only when the base (the difference between the spot price of the asset whose risk is hedged and the price of the futures contract used) can be predicted with certainty and can only be achieved if the end date of the hedging period is the same as the maturity of the futures contract used and if the physical and financial characteristics of the asset or commodity whose risk it covers are identical to those of the asset or commodity that is the subject of the futures contract (Sheu et al, 2013). If one of these conditions is missing, it is not possible to achieve perfect hedging. Thus, the risk can be reduced, but not eliminated, because the relationship between the spot price and the futures price is indeterminate, except that the two prices converge on each other at the maturity of the contract (Geppert, 1995; Kroner, 1993).

As the optimal hedging rate is given by the regression coefficient in a linear regression, the coefficient of determination $\left(\mathrm{R}^{2}\right)$ can be used to evaluate the hedging effectiveness (Chroudhry, 2003; Markopoulou et al, 2016). The coefficient of determination of a regression expresses the fraction of the dispersion of the dependent variable which is explained by the independent variable over the estimation period. If the two variables are perfectly correlated, then $R^{2}$ is equal to 1 . If they are uncorrelated, $\mathrm{R}^{2}$ is 0 .

In a regression with a single independent variable, $\mathrm{R}^{2}$ is equal to the square of the correlation coefficient between the dependent and the independent variable. In the case of hedging with futures, its effectiveness is directly related to the correlation coefficient between the change in the spot price and the futures price (Brooks et al, 2002):

$$
h=\varphi \frac{\sigma_{S}}{\sigma_{F}}=>\varphi=h \frac{\sigma_{F}}{\sigma_{S}}=>R^{2}=h^{2} \frac{\sigma_{F}^{2}}{\sigma_{S}^{2}}
$$

where $\mathrm{h}$ is the regression coefficient, in our case the optimal hedging ratio and $\sigma_{S}$ and $\sigma_{F}$ are the standard deviations of the spot and futures prices. 
$\mathrm{R}^{2}$ shows the fraction of the spot market volatility explained by the hedging instrument. If $\mathrm{R}^{2}$ is equal to 1 , in which case there is no basis risk, the position obtained by hedging has no dispersion and therefore no volatility. If $\mathrm{R}^{2}$ is equal to 0 , the dispersion of the position obtained by hedging is equal to the dispersion of a position without hedging.

Hedging efficiency measures the fraction of the market dispersion on the spot market that can be eliminated by using the optimal hedging rate over the estimation period (Yang et al, 2009; Gagnon et al., 1998). Thus, the difference $\left(1-\mathrm{R}^{2}\right)$ expresses the fraction of the market dispersion of the position on the spot market that cannot be eliminated by hedging. As in the presence of the basis risk, a statistical relationship between the changes in the futures price and in the spot one is exploited, the hedging effectiveness depends on the random error (residue) associated with this statistical relationship. When $\mathrm{R}^{2}$ is large, the volatility of the random error is small, so that the actual change in the spot price will be close to the change estimated by regression. As $\mathrm{R}^{2}$ decreases, the volatility of the random error increases and large differences can occur between the actual and estimated changes in the spot market position. It can even happen that hedging does more harm than good. This is because the volatility of the residual becomes high and, even if a positive relationship has been estimated between the change in the futures price and that of the spot, during the hedging period the futures price may increase and the spot price may decrease. Thus, in the case of a short hedge, there is a loss in both markets (Harris et al, 2010).

\section{Methodology and data}

In the previous chapter we explained how by calculating the hedge ratio, which minimizes the variance of the value of the position on the spot market, a hedging is achieved that covers the risk of the position on the spot market to a greater or lesser extent given by hedging efficiency $\left(\mathrm{R}^{2}\right)$. In order to calculate a hedging rate necessary to cover a risk over a period of time (for example one month), it is necessary to know the variation of spot and futures prices for as many such periods of time in the past (one month in this case) in order to capture the movement of the base and minimize the variance of the portfolio consisting of both spot and futures exposure. The hedging rate is a number that fixes the base at maturity, covering the risk to an extent equal to the hedging effectiveness. If the hedging efficiency is equal to 1 , then by using a hedging rate equal to that obtained by regression, a perfect hedging can be achieved (the risk is fully covered by hedging). So, the purpose of calculating the hedging rate is to fix the price at which the transaction will be performed at time $\mathrm{t} 2$ by getting the base. The disadvantage of calculating and using the hedging rate is that it requires data on the 
variation of spot and futures prices over periods equal to that of hedging and that also, in the vast majority of cases, the effectiveness of hedging is not 1 .

Thus, if one could know the basis at maturity, a hedger could calculate exactly the gain or loss to which he is exposed by using hedging with futures contracts during the hedging period. Thus, he could achieve a perfect hedging or as close to perfection as possible, maintaining the position on the futures market only as long as he gains from hedging and closing his position on the futures, when he knows that he will lose. At the same time, the hedger can know if it is good or not good for him to perform the hedging for the desired period.

In order to observe to what extent hedgers can calculate their hedging gains or losses currently, we apply an ARMA econometric model. The model will be applied to time series consisting of average values of the basis of a futures contract at a certain number of days until its maturity date.

Five futures contracts were used on the following currency pairs: AUD/CAD, EUR/USD, GBP/USD, RMB/USD and EUR/JPY, collected from Bloomberg as closing prices from the quotation day.

The following days were taken as maturity dates of the futures contracts used: June 30, 2010 (for the contract maturing in June 2010), September 30, 2010 (for the contract maturing in September 2010), December 31, 2010 (for the contract maturing in December 2010) and so on, every 3 months until June 30, 2013 deliberately including part of the global financial crisis and the period close to its end. Subsequently, for each maturity of each type of contract, a number of 91 days was considered until the maturity day. The number of days to maturity was calculated as the difference between the maturity day and the quotation date. For each number of days until maturity, the quotation of the futures contract (futures price) and the quotation of the exchange rate (spot price) related to the quotation date were taken into account and the base was calculated as the difference between the spot price and the futures price.

After finding the basis for each of the 91 days until the due date for each maturity of each contract used, the average basis by number of days until maturity was calculated. Thus, if for each contract there are 13 different maturities and on each maturity there are 91 trading days, the mean of the base for each day until the maturity date was calculated. For example, for the 13 maturities of the AUD/CAD contract there were maximum 13 different bases. The mean of these 13 values was calculated and a basis value was obtained for the AUD/CAD contract 5 days before maturity. This was done because it was necessary to obtain an evolution of the base over time depending on the number of days until maturity. Because 13 different 
maturities were used in order to better capture the evolution of the basis over as long a period of time as possible, the mean of the base values was calculated. Thus, 5 time series were obtained for each of the 5 futures contracts used, containing the evolution of the average base over a number of 91 days until maturity.

The purpose of this case study is to forecast the base for the 5 selected futures contracts with the help of the ARMA econometric model that will be applied to the time series obtained previously, which contain the evolution of the average base by number of days until maturity. Unlike classical regression models, in which $Y_{t}$ is explained by $n$ regressors $X_{1}, X_{2}, X_{3}, \ldots . X_{n}$, the ARMA model allows the variable $Y_{t}$ to be explained by its lagged values and by stochastic error terms.

It can happen that the random variable $\mathrm{Y}$ has both $\mathrm{AR}$ characteristics and MA characteristics, thus becoming a process of autoregression with moving average or ARMA (Autoregressive Moving Average). Thus, $Y_{t}$ follows an ARMA process $(1,1)$ if it can be written as

$$
Y_{t}=\theta+\alpha_{1} Y_{t-1}+\beta_{0} u_{t}+\beta_{1} u_{t-1}
$$

where $Y_{t}$ is the base at moment $t, \theta$ represents a constant, $\alpha_{1}, \beta_{0}, \beta_{1}$ are parameters, $Y_{t-1}$ is the value of the base at $t-1$ and $\mathrm{u}_{\mathrm{t}, \mathrm{u}_{\mathrm{t}-1}}$ are white noise error terms. In general, an ARMA stochastic process (n, m) consists of an AR (n) process and an MA (m) process.

This model can be applied only if the series are stationary (mean and variance remain constant in time). In order to test if the series are stationary, the autocorrelation function ACF and Augmented Dickey-Fuller unit root tests were employed. The results show that all exchange rates are $\mathrm{I}(1)$.

\section{Results and conclusions}

The forecast was performed using an ARMA model for the AUD/CAD, EUR/USD, GBP/USD series and an ARIMA model for the EUR/JPY and RMB/USD series. The objective of this methodology is to identify and estimate a statistical model that can be interpreted as having generated the data sample used in the estimation. If this estimated model is subsequently used in forecasting, it is necessary that its various characteristics be constant over time and, in particular, in the future. So, with the help of the Box-Jenkins methodology applied on the 5 series containing the evolution of the average bases on number of days until maturity related to the 5 futures contracts, predictions can be made on the evolution of the basis. This, as stated above, helps to achieve a very good hedge, maybe even perfect, the hedger knowing if he will lose or gain through this method of hedging for the period he needs or if it would be good or not to do hedging on another period. 
The equation related to this model, which will be used in estimating the base at a future time is:

$$
y_{t}=\mathrm{c}+\alpha_{1} y_{t-1}+\alpha_{2} y_{t-2}+\beta_{1} \varepsilon_{t-1}+\beta_{2} \varepsilon_{t-2}+\varepsilon_{t}
$$

where $y_{t}$ is the base at moment $\mathrm{t}$; $\mathrm{c}$ is a constant; $\alpha_{1}, \alpha_{2}, \beta_{1}, \beta_{2}$ are parameters; $y_{t-1}$ and $y_{t-2}$ are bases at $\mathrm{t}-1$ and t-2; $\varepsilon_{t}, \varepsilon_{t-1}$ and $\varepsilon_{t-2}$ are the white noise residuals.

As a result, the value of a series in a given period depends on the value of the series in the previous period and on a random error term whose expected value is 0 . Thus, the best forecast of the value of the series is its previous value.

By repeated tests we chose the model that recorded the lowest values for AIC and SIC and which has statistically significant coefficients (with p-value $<$ significance level). We found that in the case of the AUD/CAD series the model can be written as c + AR (1) + AR (2) + MA (2).

The coefficient of determination equal to 0.4765 shows that the past value of the basis explains in proportion approximately $47.65 \%$ the future value of the base (see Table 1 below).

Table 1

\section{Coefficients' estimates for series AUD/CAD}

\begin{tabular}{|c|c|r|l|l|l|r|r|r|c|}
\hline $\begin{array}{c}\text { ARMA } \\
\text { model }\end{array}$ & $\mathbf{c}$ & AR(1) & AR(2) & MA(1) & MA(2) & $\begin{array}{c}\text { S.E. of } \\
\text { regression }\end{array}$ & $\begin{array}{c}\text { Adjusted } \\
\text { R- } \\
\text { squared }\end{array}$ & $\begin{array}{c}\text { F- } \\
\text { statistic }\end{array}$ & AIC \\
\hline$(1,1)$ & $0.0032 *$ & $0.5514^{*}$ & & 0,1643 & & 0.0046 & 0.4114 & $32.459^{*}$ & -7.897 \\
\hline$(1,2)$ & 0.0030 & 0.6053 & 0.2580 & 0.0494 & $-0.4179 *$ & 0.0044 & 0.4521 & 19.3566 & -7.936 \\
\hline$(2,1)$ & 0.0030 & 0.6053 & 0.2580 & 0.0493 & -0.4179 & 0.0044 & 0.4520 & 19.3566 & -7.936 \\
\hline$(2,2)$ & 0.0030 & 0.6053 & 0.2580 & 0.0493 & -0.4179 & 0.0044 & 0.4520 & 19.3566 & -7.936 \\
\hline
\end{tabular}

Source: Authors' own calculation.

The equation for AUD/CAD is:

$$
y_{t}=0.0032+0.5514 y_{t-1}+0.7867 y_{t-2}-0.4179 \varepsilon_{t-2}
$$

In the case of the EUR / JPY series, the model will be an ARIMA type due to the I(1) integration of the series. Applying the same criteria, the resulting model is AR (1) $+\mathrm{AR}(2)+\mathrm{MA}(1)+\mathrm{MA}$ (2). The coefficient of determination equal to 0.1896 shows that the past base explains approximately $19 \%$ of the future value of the base (see Table 2). 
Coefficients' estimates for series EUR/JPY

\begin{tabular}{|c|c|c|c|c|c|r|r|r|r|}
\hline $\begin{array}{c}\text { ARMA } \\
\text { model }\end{array}$ & $\mathbf{c}$ & AR(1) & AR(2) & MA(1) & MA(2) & $\begin{array}{c}\text { S.E. of } \\
\text { regress } \\
\text { ion }\end{array}$ & $\begin{array}{c}\text { Adjuste } \\
\text { d R- } \\
\text { squared }\end{array}$ & $\begin{array}{c}\text { F- } \\
\text { statistic }\end{array}$ & AIC \\
\hline$(1,1)$ & $-5.22 \mathrm{E}-07$ & $0.4410^{*}$ & & -0.8415 & & 0.0002 & 0.1460 & 8.6078 & -14.044 \\
\hline$(1,2)$ & $-1.30 \mathrm{E}-06$ & 1.1543 & -0.6861 & -1.5422 & 0.7445 & 0.0001 & 0.2653 & 8.9465 & -14.164 \\
\hline$(2,1)$ & $-1.30 \mathrm{E}-06$ & 1.1543 & -0.6861 & -1.5422 & -0.4179 & 0.0044 & 0.4520 & 19.3566 & -7.936 \\
\hline$(2,2)$ & $-1.10 \mathrm{E}-06$ & & 0.3244 & & -0.6316 & 0.0002 & 0.0725 & 4.4430 & -13.952 \\
\hline
\end{tabular}

Source: Authors' own calculation.

The EUR/JPY equation is:

$y_{t}=1.1543 y_{t-1}-0.6861 y_{t-2}-1.5422 \varepsilon_{t-1}+0.7445 \varepsilon_{t-2}$

Moving on to the EUR/USD contract, we will see that the independent variable explains about $13 \%$ of the evolution of the dependent variable. The ARMA model will be one of the type c + AR (1) (see Table 3):

Table 3

\section{Coefficients' estimates for series EUR/USD}

\begin{tabular}{|c|c|r|r|r|r|r|r|r|r|}
\hline $\begin{array}{c}\text { ARMA } \\
\text { model }\end{array}$ & $\mathbf{c}$ & AR(1) & AR(2) & MA(1) & MA(2) & $\begin{array}{c}\text { S.E. of } \\
\text { regression }\end{array}$ & $\begin{array}{c}\text { Adjusted } \\
\text { R-squared }\end{array}$ & $\begin{array}{c}\text { F- } \\
\text { statistic }\end{array}$ & \multicolumn{1}{|c|}{ AIC } \\
\hline$(1,1)$ & 0.008 & 0.158 & & 0.21 & & 0.005 & 0.1271 & 7.556 & -7.642 \\
\hline$(1,2)$ & 0.008 & 0.855 & -0.013 & -0.546 & -0.044 & 0.005 & 0.2000 & 6.563 & -7.717 \\
\hline$(2,1)$ & 0.008 & 0.855 & -0.013 & -0.546 & -0.044 & 0.005 & 0.2000 & 6.563 & -7.717 \\
\hline$(2,2)$ & 0.008 & & 0.089 & & 0.136 & 0.005 & 0.0389 & 2.803 & -7.554 \\
\hline
\end{tabular}

Source: Authors' own calculation.

The equation becomes:

$y_{t}=0.0089+0.8555 y_{t-1}$

The equation for the GBP/USD contract is:

$y_{t}=1.1616 y_{t-1}+0.839 y_{t-2}-0.2961 \varepsilon_{t-2}$ 
It is important to mention here that the coefficient of determination shows that the base of the future is explained in proportion of about $65 \%$ by the base of the past. And the best performing ARMA model is c + AR (1) + AR (2) + MA (2) (see Table 4):

Table 4

\section{Coefficients' estimates for series GBP/USD}

\begin{tabular}{|c|c|c|c|c|r|r|r|r|r|}
\hline $\begin{array}{c}\text { ARMA } \\
\text { model }\end{array}$ & $\mathbf{c}$ & AR(1) & AR(2) & MA(1) & MA(2) & $\begin{array}{c}\text { S.E. } \\
\text { of } \\
\text { regression }\end{array}$ & $\begin{array}{c}\text { Adjusted } \\
\text { R- } \\
\text { squared }\end{array}$ & $\begin{array}{c}\text { F- } \\
\text { statistic }\end{array}$ & AIC \\
\hline$(1,1)$ & 0.0029 & 0.7345 & & 0.1684 & & 0.0058 & 0.6448 & 82.698 & -7.4256 \\
\hline$(1,2)$ & 0.0039 & 1.1616 & -0.2108 & -0.3229 & -0.2961 & 0.0057 & 0.6500 & 42.326 & -7.4302 \\
\hline$(2,1)$ & 0.0039 & 0.8555 & -0.0135 & -0.3229 & -0.2961 & 0.0057 & 0.6500 & 42.326 & -7.4302 \\
\hline$(2,2)$ & 0.0041 & & 0.8390 & & -0.4045 & 0.0074 & 0.4117 & 32.151 & -6.9321 \\
\hline
\end{tabular}

Source: Authors' own calculation.

The equation of the series corresponding to the RMB / USD contract is:

$y_{t}=1.1543 y_{t-1}-0.6861 y_{t-2}-1.5422 \varepsilon_{t-1}+0.7445 \varepsilon_{t-2}$

So, the best performing ARIMA model is AR (1) + AR (2) + MA (1) + MA (2). The coefficient of determination of 0.1896 shows that the change of the independent variable explains in proportion of about $19 \%$ the evolution of the dependent variable (see Table 5).

Table 5

\section{Coefficients' estimates for series RMB/USD}

\begin{tabular}{|c|c|c|c|c|c|r|r|r|r|}
\hline $\begin{array}{c}\text { ARMA } \\
\text { model }\end{array}$ & $\mathbf{c}$ & AR(1) & AR(2) & MA(1) & MA(2) & $\begin{array}{c}\text { S.E. of } \\
\text { regression }\end{array}$ & $\begin{array}{c}\text { Adjusted } \\
\text { R- } \\
\text { squared }\end{array}$ & $\begin{array}{c}\text { F- } \\
\text { statistic }\end{array}$ & AIC \\
\hline$(1,1)$ & $-5.22 \mathrm{E}-07$ & 0.4410 & & -0.8415 & & 0.0002 & 0.1460 & 8.6078 & -14.04 \\
\hline$(1,2)$ & $-1.30 \mathrm{E}-06$ & 1.1543 & -0.6861 & -1.5422 & 0.7445 & 0.0001 & 0.2653 & 8.9465 & -14.16 \\
\hline$(2,1)$ & $-1.30 \mathrm{E}-06$ & 1.1543 & -0.6861 & -1.5422 & 0.7445 & 0.0001 & 0.2653 & 8.9465 & -14.16 \\
\hline$(2,2)$ & $-1.10 \mathrm{E}-06$ & & 0.3244 & & -0.6316 & 0.0002 & 0.0725 & 4.4430 & -13.95 \\
\hline
\end{tabular}

Source: Authors' own calculation.

In this paper, a different way of approaching hedging with futures contracts was presented using an ARMA econometric model. It was shown that the classical 
approach of calculating the optimal hedging rate is equivalent to some extent to forecasting the base, because in both cases it is fixed, the ultimate goal being to set the price at which the transaction will be made. Thus, knowing the base for the future, a hedger, depending on its position on the futures market (long or short), can say whether it will win or lose by hedging for the desired period. He can thus figure out whether or not it is appropriate to hedge and for what period of time.

In order to forecast the base at a future time $t$, data was taken for 5 futures contracts and 5 time series were created containing the evolution of the average base by number of days until maturity. Subsequently, in order to be able to apply the forecasting methodology with the help of the ARMA econometric model, their stationarity was tested with the help of the analysis of autocorrelations and partial autocorrelations and with the help of the "unit root" tests. It was found that 3 of the 5 series are stationary, the other two being stationary only after calculating the first difference, resulting in an integrated series of degree 1. Using the ARMA methodology, respectively ARIMA, we could predict the base and calculate, based on standard errors, the actual values of the base with a certain number of days before maturity with a $95 \%$ confidence intervals. Thus, hedgers can use, in addition to the classical approach to calculating the hedging rate that reduces the volatility of their position, this econometric methodology for forecasting the base, using a hedging rate equal to 1 . However, despite the fact that the econometric model found is an adequate application of the series data, its application in forecasting is risky and this is because: the coefficients of the regression equations are in turn estimated with a standard error, there is a risk that the use of the average base does not capture in the best possible way the evolution of the base on a certain contract for $\mathrm{x}$ days until maturity, the lack of data for certain days reduced the data selection used in the calculation of the average base and last but not least, because unforeseen events, which can greatly affect spot and futures prices, were not and cannot be taken into account.

\section{References}

1. Adler, M., Dumas, B. (1984). Exposure to currency risk: Definition and measurement. Financial Management, 13, pp. 41-50.

2. Alvarez-Diez, S., Alfaro-Cid, E., Fernandez-Blanco, M. O. (2016). Hedging foreign exchange rate risk: multi-currency diversification. European Jounal of Management and Business Economics, 25(1), pp. 2-7.

3. Andersen, T. G., Bollerslev, T., Diebold, F. X., Labys, P. (2003). Modelling and forecasting realized volatility. Econometrica, 71(2), pp. 579-625.

4. Brooks, C., Henry, O. T., Persand, G. (2002). The effect of asymmetries on optimal hedge ratios. The Journal of Business, 75(2), pp. 333-352. 
5. Brown, G. W., Crabb, P. R., Haushalter, D. (2006). Are firms successful at selective hedging?. The Journal of Business, 79(6), pp. 2925-2949.

6. Chroudhry, T. (2003). Short run deviations and optimal hedge ratios: evidence from stock futures. Journal of Multinational Financial Management, 13, pp. 171-192.

7. Collins, R. A. (1997). Toward a Positive Economic Theory of Hedging. American Journal of Agricultural Economics, 79(2), pp. 488-499.

8. Francis, B., Hasan, I., Pantzalis, C. (2007). Operational hedges and foreign exchange exposure: the experience of U.S. MNCs during the Asian financial crisis. Advances in Financial Economics, 12, pp. 445-479.

9. Gagnon, L., Lypny, G.L., McCurdy, T.H. (1998). Hedging foreign currency portfolios, Journal of Empirical Finance, 5(3), pp. 197-220.

10. Geppert, J. M. (1995). A statistical model of the relationship between futures contracts hedging effectiveness and investment horizon length. The Journal of Futures Markets, 15, pp. 507-536.

11. Hagelin, N. (2003). Why firms hedge with currency derivatives: An examination of transaction and translation exposure. Applied Financial Economics, 13, pp. 55-69.

12. Harris, R. D., Shen, J., Stoja, E. (2010). The limits to minimum-variance hedging. Journal of Business Finance \& Accounting, 37(5-6), pp. 737-761.

13. Howe, M. A., Rustem, B., Selby, M.J.P. (1996). Multi-period minimax hedging strategies, European Journal of Operational Research, 93(1), pp. 185-204.

14. Hull, J. C. (2018). Options, futures and other derivatives, Tenth Edition, Pearson.

15. Johnson L.L. (1976). The Theory of Hedging and Speculation in Commodity Futures. In: The Economics of Futures Trading. Palgrave Macmillan, London

16. Kroner, K. F., Sultan, J. (1993). Time-varying distributions and dynamic hedging with foreign currency futures. Journal of Financial and Quantitative Analysis, 28, pp. 535-551.

17. Markopoulou, C. E., Skintzi, V. D., Refenes, A-P, N. (2016). Realized hedge ratio: predictability and hedging performance. International Review of Financial Analysis, 45, pp. 121-133.

18. Pennings, J., Garcia, P. (2004). Hedging behaviour in small and mediumsized enterprises: the role of unobserved heterogeneity. Journal of Banking and Finance, 28, pp. 951-978. 
19. Schena, P. J. (2007). Measuring and managing the foreign exchange exposure of Chinese companies. International Finance Review, (7), pp. 285-306.

20. Schweizer, M. (1994). Risk-minimizing hedging strategies under restricted information, Mathematical Finance, 4(4), pp. 327-342.

21. Sheu, H. J., Lai, Y. S. (2013). Incremental value of a futures hedge using realized ranges. Journal of Futures Markets, 34(7), pp. 676-689.

22. Smith, C. A., Stulz, R. (1985). The Determinants of Firms' Hedging Policies, Journal of Financial and Quantitative Analysis, 20(4), pp. 391-405.

23. Solomon, J. F., Joseph, N. L. (2000). Which corporate hedging motives are appropriate? An institutional shareholders' perspective. International Journal of Finance and Economics, 5, pp. 339-347.

24. Su, S. (2018). An investigation of foreign exchange risk management in Chinese multinational companies compared with US and UK MNEs. Paper presented at $20182^{\text {nd }}$ International Conference on Management, Education and Social Sciences, Qingdao, China.

25. Yang, C. C., Brockett, P. L., Wen, M-M. (2009). Basis risk and hedging efficiency of weather derivatives, Journal of Risk Finance, 10(5), pp. 517-535. 